Temmink, D., Francke, A.L., Kerkstra, A., Huyer Abu-Saad, H. Dutch transmural nurse clinics for chronic patients: a descriptive study. Patient Education and Counseling: 2000, 39(2-3), 177-184

\begin{tabular}{|c|c|}
\hline $\begin{array}{l}\text { Postprint } \\
\text { Version }\end{array}$ & 1.0 \\
\hline Journal website & http://dx.doi.org/doi:10.1016/S0738-3991(99)00020-8 \\
\hline Pubmed link & $\begin{array}{l}\text { http://www.ncbi.nlm.nih.gov/entrez/query.fcgi?db=pubmed\&cmd=Retrieve\&do } \\
\text { pt=Abstract\&list uids=11040717\&query hl=28\&itool=pubmed docsum }\end{array}$ \\
\hline DOI & 10.1016/S0738-3991(99)00020-8 \\
\hline
\end{tabular}

This is a NIVEL certified Post Print, more info at http://www.nivel.eu

\title{
Dutch transmural nurse clinics for chronic patients: a descriptive study
}

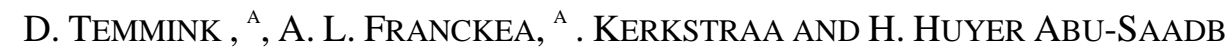

${ }^{a}$ NIVEL, Netherlands Institute of Primary Health Care, P.O. Box 1568, 3500 BN

Utrecht, The Netherlands

${ }^{\mathrm{b}}$ Maastricht University, Faculty of Health Sciences, Department of Nursing Science, Maastricht, The Netherlands

Received 3 August 1998; revised 6 January 1999; accepted 7 February 1999.

Available online 21 December 1999.

\section{Abstract}

'Transmural care' can be defined as patient-tailored care provided on the basis of close collaboration and joint responsibility between hospitals and home care organizations. One form of transmural care is transmural nurse clinics for chronically ill. This study describes 62 transmural nurse clinics in the Netherlands. It was established that most of these nurse clinics are held by a specialized community nurse at a hospital outpatient clinic. The principal tasks of the specialized nurse at the clinic are providing illness-related information and supporting patients in dealing with the illness. Only a few unpublished evaluations of Dutch transmural nurse clinics have been conducted. Future research has to provide more insight into the impact of transmural nurse clinics on the quality and continuity of care.

\section{INTRODUCTION}

'Transmural care' is a new concept in Dutch health care which was introduced at the beginning of the 1990s and has been a rapidly growing field since then [1]. The concept refers to care which breaks down the traditional walls between hospital and primary care, is tailored to patients' needs and provided on the basis of close collaboration and joint responsibility by primary care and hospital organizations [2]. Close collaboration means collaboration between professionals on a formal structural basis which can, for instance, be seen in regular meetings in which both patient-related subjects as well as pre-conditions of the transmural care process are discussed. Joint responsibility refers to formal agreements about the transmural care process at an organizational level. Such agreements can be written down in protocols or guidelines which, for instance, contain information about who, or what organization, assigns the location for transmural care or who organizes professionals providing transmural care.

Transmural objectives are to improve co-operation and phasing between hospital and primary care organizations. Transmural care is considered an important innovation, 
Temmink, D., Francke, A.L., Kerkstra, A., Huyer Abu-Saad, H. Dutch transmural nurse clinics for chronic patients: a descriptive study. Patient Education and Counseling: 2000, 39(2-3), 177-184

particularly in the care for chronic patients, since the chronically ill are often confronted with disabilities in their daily life and require help from several health care professionals in different settings [3]. The expectation is that in transmural care, hospital and primary care professionals will collaborate more than is the case in traditional care and make more reciprocal use of expertise. In addition, it is expected that transmural care will result in better quality and continuity of care for chronic patients [2].

The transmural care concept is not often used outside the Netherlands. However, in the United Kingdom the related concept of 'shared care' is an important issue on the health care policy agenda [4]. This English language concept is primarily used to indicate the integration of general practitioner care and home care services. Secondly, shared care encompasses cooperation between primary and hospital care. This second aspect of shared care, in particular, is comparable with the Dutch transmural care concept. In other European countries, the integration of primary and hospital care has also received a lot of attention. For instance, Sweden is also oriented towards a more integrated form of health care organization in which primary and hospital care services co-operate [5]. However, the way in which primary and hospital care are integrated can vary from one country to another. Outside the Netherlands, integration is often achieved by reorganization of the system of funding and management of the organizations involved [4]. In the Netherlands, the care needs of a specific chronic patient group often form the point of departure for transmural care innovation [4].

Three main categories of transmural care can be distinguished in Dutch health care [6]. First, transmural care delivered by specialist hospital and generalist primary care providers together is identified. This category can, for instance, be made operational by delivering hospital-based-home-care in close co-operation with a home care organization. A second category of transmural care is transmural care during admission to and discharge from a specialized care organization (e.g. a hospital), delivered by generalist primary care professionals. Within this category of transmural care, liaison nurses are often involved. In the Netherlands, these nurses are frequently employed by a home care organization, but work in a hospital in which they are responsible for the transfer of patients from hospital to home and vice versa. A third category is transmural care delivered by generalist primary care professionals who are supported by specialist hospital professionals. Transmural care with this characteristic can be practised by, for instance, specialized community nurses who hold outpatient clinics in a hospital and who work closely together with a medical specialist. In such transmural nurse clinics both the hospital as well as the home care organization are responsible for matters such as: the content of the clinic, the tasks of nurses holding the clinic and the inter- and intradisciplinary collaboration between professionals. Transmural nurse clinics are often implemented to meet patients demands for education and counseling; these are care activities which often receive insufficient attention during medical outpatient clinics.

Despite the Dutch interest in transmural care in general and transmural nurse clinics in particular, a systematic overview of the characteristics of these clinics is not available. This article aims to shed more light upon the structural/organizational, process and outcome characteristics of transmural nurse clinics. On the basis of the information in this article, policy makers and health professionals, both in, as well as, outside the Netherlands, will be better able to judge whether transmural nurse clinics may also be useful in their situation. In addition, this article may function as the impetus to starting transmural nurse clinics and research in the field.

The following research questions are addressed in this article:

(1) What are the structural/organizational characteristics of Dutch transmural nurse clinics for somatic patients?

(2) What are process characteristics of these clinics?

(3) Are these clinics evaluated? If so, what methods are used and what outcome characteristics are described? 
Temmink, D., Francke, A.L., Kerkstra, A., Huyer Abu-Saad, H. Dutch transmural nurse clinics for chronic patients: a descriptive study. Patient Education and Counseling: 2000, 39(2-3), 177-184

Before answering the research questions posed, we first present the methods used for tracking down transmural nurse clinics and the procedures for processing and analysing the data.

\section{METHODS}

\subsection{Sources and data collection}

The following Dutch sources were studied in the period January-June 1996 to track down names and telephone numbers of contacts in transmural nurse clinics:

(1) Innovative Care Projects Database [7]

(2) Registered Scientific Research Database [8]

(3) Research and Development Database [9]

(4) Inventarization of Research and Development projects in home care [10]

(5) Member list of the transmural network [11]

(6) Member lists of nursing organizations, that is:

(a) association of Dutch rheumatology nurses

(b) association of Dutch Chronic Non Specific Lung Disease (CNSLD) nurses

(c) transmural nurses employed by a regional co-ordination centre for chronic illnesses.

In addition to the sources mentioned, the 'snowball method' was used: contacts at transmural nurse clinics (often the specialized nurse who held the clinic or a nursing manager) were asked whether they knew other persons or organizations involved in transmural nurse clinics.

A total of 103 persons were contacted by telephone. To judge whether a nurse clinic had a transmural character, the contact was asked whether the services at the relevant clinic were provided on the basis of close collaboration and joint responsibility, as defined in the introduction to this article, between a hospital and home care organization. If both close collaboration and joint responsibility were used, the contact was asked whether he/she had any reports (e.g. project plans, annual reports or evaluation reports) that could provide information about the structure/organization, process or outcome characteristics of the transmural clinic. Structural/organizational characteristics are relatively stable characteristics like collaborating and funding organizations. Process characteristics encompass, for instance, target groups, goals and nursing activities that go on within and between care providers and patients. Outcome characteristics refer to a change in a patient's current and future health status that can be attributed to antecedent health care [12].

When respondents did not have any reports that could provide a valid picture of the characteristics of the clinic, a questionnaire developed by the researchers was sent covering the same items as mentioned above.

Sixty-five of the 103 telephone contacts were involved with 78 transmural nurse clinics (some people were involved with more than one clinic). The other 38 were not involved in transmural nurse clinics, but in other transmural innovations or in non-transmural nurse clinics.

Information on 35 of the 78 transmural nurse clinics was provided by reports and on 27 by postal questionnaire. Sixteen of the 78 clinics tracked down provided either nothing or incomplete data; ten of these clinics had either just or had not yet started, contacts from five clinics did not respond and one clinic started was no longer operational. Accordingly, the results presented are based on the information available from 62 operational transmural nurse clinics for chronic patients.

\subsection{Procedures for processing and analysing the data}

The information gained from the reports and questionnaires was summarized by the researchers separately for each transmural nurse clinic. This transmural nurse clinic summary was sent to the contact who was requested to make corrections or changes, as needed. The changes made were then coded and stored in SPSS/PC, which is a Statistical 
Temmink, D., Francke, A.L., Kerkstra, A., Huyer Abu-Saad, H. Dutch transmural nurse clinics for chronic patients: a descriptive study. Patient Education and Counseling: 2000, 39(2-3), 177-184

Package for the Social Sciences. Descriptive statistics were used to analyze the data. Subsequently, a draft report of the results was sent to all respondents who were again asked to respond if their clinic was correctly described. These latter adjustments were integrated in the final analyses and report.

\section{RESULTS}

\subsection{Structural/organizational characteristics}

\subsubsection{Collaboration, employment institution and financing}

The 62 transmural nurse clinics described all started post 1988, but most clinics $(n=42)$ started in the last two years. As is inherent in the transmural character of the clinics, formal agreements about collaboration and responsibilities for the care delivered from one or two home care organizations and one or two hospitals were made for all 62 transmural nurse clinics. All clinics were run under joint responsibility of the hospital(s) and home care organization(s). In four of the 62 transmural nurse clinics, respondents also mentioned a regional co-ordination centre for chronic illnesses as a collaborating partner, while in three of the 62 transmural nurse clinics general practitioners were also involved.

Fifty-four out of the 62 transmural nurse clinics were held at a hospital outpatient clinic. Three clinics were run in a home care building and three others were held alternately at a hospital outpatient clinic and in the building of a home care organization. Two transmural clinics were held at a practice of a general practitioner.

Close collaboration and joint responsibilities for the clinics was, for instance, expressed in the employment of nurses running the clinics and the location of the clinics. In more than a half of the clinics $(n=36)$ the specialist nurses who head them were officially employed by a home care organization. In a quarter of the transmural nurse clinics $(n=18)$, the specialist nurse was employed by both a home care agency and a hospital. In seven other clinics, the specialist nurse was employed by the hospital alone. Despite the fact that the hospital was the sole employer in these clinics, we do regard them as transmural clinics. In these situations, agreements about collaboration and joint responsibility between the hospital and home care organization are evidenced in regular meetings between employees of the home care organization and the hospital. The fact that the nurse who heads the clinic can make use of the facilities of the home care organization and visit patients at home illustrates the transmural character of these clinics as well.

Half of the transmural nurse clinics $(n=31)$ were only funded by the regular budgets of the organizations involved; often both the home care organization and the hospital funded the clinic. In about one third of the transmural nurse clinics $(n=19)$ external organizations (e.g. insurance companies, Dutch Ministry of Health or National Centre for Nursing and Care) also funded the clinic. Three clinics were only funded by the hospital; two only by an external organization and two others only by a home care organization. No information on funding was available from five of the clinics.

\subsubsection{Professional background}

About $80 \%$ of the transmural nurse clinics were held by nurses who, following their basic training, had followed a 10-day course in nursing care for a specific patient group (for instance rheumatics or diabetics). Three transmural nurse clinics were held by nurses who had followed an 18-months certified post-basic nurse specialist program after basic nursing training. The remaining transmural nurse clinics were held by a nurse who had not followed any specific additional course.

\subsection{Process characteristics}

\subsubsection{Target groups}


Temmink, D., Francke, A.L., Kerkstra, A., Huyer Abu-Saad, H. Dutch transmural nurse clinics for chronic patients: a descriptive study. Patient Education and Counseling: 2000, 39(2-3), 177-184

All 62 clinics targeted patients with chronic disease. On the basis of the medical diagnosis, four types of clinics could be distinguished: (1) clinics for rheumatics, (2) clinics for diabetics, (3) clinics for patients with CNSLD, and (4) 'other' clinics (see Table 1). This last type includes clinics which were for patients with a colostomy, stroke, cancer, multiple sclerosis, cystic fibrosis or Parkinson’s disease.

\section{[TABLE 1]}

All four types of clinics were oriented towards patients who had a need for information about their disease or its consequences in daily life. Patients who found it difficult to accept their illness or had more practical questions, e.g. about financial compensation for adapting their homes, were also able to visit the clinic.

Clinics for rheumatics, diabetics and the 'other clinics' were mostly for adults, while transmural nurse clinics for patients with CNSLD were more often only for children.

\subsubsection{Goals of the clinics}

Goals of the transmural nurse clinics were often formulated as improving the quality or continuity of care. For example, the quality of care could be improved because the medical specialist who referred patients to the transmural clinic, now made more use of the expertise of the specialist (community) nurse, and vice versa. The continuity of care could, for instance, be improved because the transmural nurse clinic was situated at the same outpatient clinic in which the medical specialist provided patient consultations. Visits to the medical specialist and the specialist nurse could then be arranged on the same day.

A more specifically formulated goal mentioned by respondents of rheumatology, CNSLD, and 'other' clinics was 'improving patient education'. At a transmural nurse clinic, the specialist nurse could give patients information additional to the information given by the specialist.

In addition to 'improving quality of care', respondents from diabetes clinics often mentioned 'preventing hospitalization' and 'improving interdisciplinary co-operation' as goals of the transmural nurse clinic. During the clinic, the specialist nurse gave patients information about foot inspection, which could reduce incidence of hospitalization. As the nurses were employed by both a home care organization and a hospital they are able to contact care providers of both organizations, this may lead to a better interdisciplinary cooperation.

\subsubsection{Referrals}

In all transmural nurse clinics, a majority of the patients were referred by medical specialists. Fifty per cent of the respondents mentioned that the transmural nurse clinic was also attended by patients who come on their own initiative. About $40 \%$ of the respondents, in rare cases, mentioned a general practitioner as having referred them. Health care providers in general, nurses and dieticians were also mentioned (in 26, 21 and 5\% of clinics, respectively) as referrers to clinics.

\subsubsection{The tasks of the specialist nurse at the transmural nurse clinic}

Two most frequently reported nursing tasks were giving patient education and counseling to patients. Patient education was specified as a nursing task in almost all transmural nurse clinics (see Table 2). Practical aids and adapting the home were the main topics on which patients received information. For example, rheumatics received information about how to request a special chair or special footwear, while parents of asthmatic children received information about how to use inhalers. Respondents from diabetes clinics frequently mentioned teaching patients to use a blood-testing kit for blood-glucose during a consultation at the clinics. During a transmural nurse clinic, nurses can reduce patient anxiety about using these kits, by telling them of the importance of monitoring these values 
Temmink, D., Francke, A.L., Kerkstra, A., Huyer Abu-Saad, H. Dutch transmural nurse clinics for chronic patients: a descriptive study. Patient Education and Counseling: 2000, 39(2-3), 177-184

themselves.

\section{[TABLE 2]}

Giving counseling or psychosocial support was reported in more than $40 \%$ of the transmural nurse clinics (see Table 2). Often, the specialist nurse functions as a 'sympathetic listener' for the patient. This can, for instance, be important in creating acceptance of the illness and in dealing with increasing dependence on the partner, family or professionals.

Careful assessment of the patients' problems and care needs was mentioned in one third of the transmural nurse clinics as one of the tasks of the specialist nurse (see Table 2). Often by using a standard history form, the nurse first assessed the patients' physical and psychosocial problems. In about twenty per cent of the clinics, the specialist nurse can refer patients to other health care professionals and guide them through the web of health care organizations and institutions.

Table 2 shows that the 'foot inspection' is mentioned in a quarter of the diabetes clinics. Particularly older diabetes patients frequently have problems with their circulation, so foot tissue damage can be a problem. Structural check of the patients' feet may prevent tissue damage.

\subsubsection{Additional tasks}

In all cases, the specialist nurse had other tasks in addition to the consultations at the transmural nurse clinic. Six categories of additional tasks can be distinguished: (1) direct patient care outside the clinic, (2) improving the competence of professionals, (3) the coordination and organization of care, (4) innovation and health care management, (5) research, and (6) other tasks (see Table 3).

\section{[TABLE 3]}

Most of the additional tasks mentioned were related to 'direct patient care outside the clinic'. For example, specialist nurses visit patients at home or give consultations by telephone. Before nurses can give patients advice about adapting the home, they need to know this environment. By visiting the patient at home, the nurse is able to give advice which is better suited to the patients needs.

Another frequently reported additional task for the specialist nurse was to improve the competence of other professionals. Specialist nurses who head transmural nurse clinics, for example, also give lectures and provide consultations to hospital and community nurses. Co-ordination of care was mentioned as additional task in 28 transmural nurse clinics (see Table 3). Co-ordination is important because chronic patients are often treated by several care providers and coordination makes clear who is to do what. Consequently, a lot of nurses who head the clinics have regular, interdisciplinary meetings with medical specialists, occupational therapists, physiotherapists, etc.

A fourth additional reported task concerns 'innovation and health care management'. About $40 \%$ of the contacts reported that the specialist nurse who headed the clinic also developed care protocols and ensured optimal conditions for the transmural nurse clinic involved.

3.3. Outcome characteristics

According to the respondents, 21 of the 62 transmural nurse clinics presented have been evaluated. However, four of those respondents provided no information about the evaluation conducted, so we have insight into 17 evaluations. The evaluation outcomes presented by respondents indicate positive effects on the quality or continuity of care or effects on the use of health care facilities. These outcomes are often formulated in terms of satisfaction of clients or professionals. However, since satisfaction judgements will always be determined by what is a social desirable response, only asking about satisfaction does not give a valid picture of the quality or continuity of care. Moreover, shortcomings in the design of the evaluations make it difficult to interpret reported outcomes. In almost all of the evaluations $(n=16)$, a research design with post-tests only was used, while in only one case a pre-test was 
Temmink, D., Francke, A.L., Kerkstra, A., Huyer Abu-Saad, H. Dutch transmural nurse clinics for chronic patients: a descriptive study. Patient Education and Counseling: 2000, 39(2-3), 177-184

carried out. Control groups or validated measurement instruments were not used in any of the evaluations.

\section{CONCLUSIONS AND DISCUSSION}

In several western industrialized countries, innovations are introduced into the care of chronic patients [4 and 5]. In such innovations, primary and secondary care services are often integrated. This kind of integrated care is often called 'transmural care' in the Netherlands. The present descriptive study gives insight into characteristics of 62 Dutch transmural nurse clinics. The nurse clinics are considered 'transmural' since they are provided on the basis of close collaboration and joint responsibility by hospitals and home care organizations.

Firstly, the structural/organizational characteristics of transmural nurse clinics were described. It appeared that transmural nurse clinics were most often held at a hospital outpatient clinic and were mostly financed by the regular budgets of the organizations involved (e.g. a home care organization and a hospital). The professional background of nurses heading a transmural nurse clinic differs. These nurses have different professional backgrounds ranging from nurses who did not follow any specific training course for the patient group involved, after their basic nursing training, to nurses who followed an extended eighteen month programme of training. More insight into the appropriate background for nurses heading transmural nurse clinics seems needed to direct the training of these nurses. Secondly, process characteristics of Dutch transmural nurse clinics have been described. The clinics were oriented towards rheumatic patients, diabetics, patients with CNSLD and other chronic patients (for instance patients with cancer, multiple sclerosis or Parkinson's disease). This orientation towards the chronically ill is not surprising; a lot of chronic patients are confronted with disabilities in their daily life and require help from several health care professionals [3].

Patients are most often referred to a transmural nurse clinic by a medical specialist. This indicates that collaboration within the framework of the transmural nurse clinics is often limited to medical specialists only and the specialist nurses heading the clinics. On the basis of the results of our descriptive study, it can be concluded that general practitioners seldom have a role in transmural nurse clinics.

In almost all transmural nurse clinics, patient education is specified as a nursing task. In addition to this, during a consultation at the transmural clinic, the specialist nurses give counseling or psychosocial support to patients, which is helpful in dealing with the illness. Apart from the tasks at the transmural nurse clinic, the specialist nurses provide, when necessary, direct patient care outside the clinic (e.g. by home visits or consultations by telephone). This fact that nurses perform tasks in the hospital outpatient clinic as well as in the home setting, might be important in improving the communication, co-operation and match between professionals in the two settings mentioned. Patients might also have better quality and continuity of care because they receive care both in and outside the hospital from one specialist nurse who is familiar with their individual situation and problems.

Finally, evaluations and outcomes of transmural nurse clinics have been the subject of this descriptive study. Despite the positive expectations of transmural nurse clinics on, for instance, continuity and quality of care, evaluation studies with methodological qualities supporting these expectations are lacking. Few uncontrolled evaluations of Dutch transmural nurse clinics have been conducted and the effects on continuity and quality of care are still rather unclear. This is to a large extent due to methodological weaknesses; pre-tests, validated measurement tools and control groups often being absent. Consequently, future scientific research is needed to gain insight into effects of Dutch transmural nurse clinics on quality and continuity of care. Results of such future research will give insight in the desirability of implementing transmural nurse clinics on a large scale both in and outside the Netherlands. 
Temmink, D., Francke, A.L., Kerkstra, A., Huyer Abu-Saad, H. Dutch transmural nurse clinics for chronic patients: a descriptive study. Patient Education and Counseling: 2000, 39(2-3), 177-184

\section{REFERENCES}

1. B.A. van der Linden, Transmural care. Facts and future. In: Health and Health Care in the Netherlands De Tijdstroom, Utrecht (1997), pp. 181-188.

2. Nationale Raad voor desgezondheid \& College voor Ziekenhuisvoorzieningen, .

Transmurale somatische zorg: Advies van de Nationale Raad voor desgezondheid en het College voor Ziekenhuisvoorzieningen (Somatic Transmural Care: Advise of the National Council for Public Health and the National Board for Hospital Facilities) NRV/CvZ, Zoetermeer (1995).

3. G.A.M. van den Bos, The burden of chronic diseases in terms of disability, use of health care and healthy life expectancies. Eur J Public Health 5 (1995), pp. 29-34.

4. Julius Centrum voor Patiëntgebonden Onderzoek, . Congres-folder: Transmurale zorg, managed care, disease management en integrated care vergeleken (Congress-brochure: Transmural care, managed care, disease management and integrated care compared) Universiteit van Utrecht, Utrecht (1998).

5. C. Häggmark and B. Nilsson, Effects of an intervention programme for improved discharge-planning. The frequency of re-admissions, problems and treatments of cancer patients receiving repeated treatments in hospital. Vård I Nord 17 (1997), pp. 4-8.

6. Francke AL. Transmurale zorg: begrippen, beleidsontwikkelingen en basisvormen. In: Jaarboek Verpleegkunde 1997. Thema: Transmurale zorg, pp. 17-35 (Transmural care: concepts, policy developments and primary forms. In: Nursing Yearbook 1997. Theme: Transmural care), Kavanah, Dwingelo, 1997..

7. NIVEL, Trimbos-instituut \& NZi, . Innovatie in de zorgsector, jaarboek 1996 (Innovation in care, yearbook 1996) Uitgeverij De Tijdstroom BV, Utrecht (1996).

8. NIVEL, . Registratie Wetenschappelijk Onderzoek eerstelijnsgezondheidszorg 1995-1996 (Registration Scientific Research 1995-1996) 24 NIVEL, Utrecht (1996).

9. Landelijk Centrum Verpleging \& Verzorging, . Databank Onderzoek \& Ontwikkeling (Research and Development Database) LCVV, Utrecht (1996).

10. Landelijke Vereniging voor Thuiszorg \& Stichting Onderzoek en Ontwikkeling Maatschappelijke gezondheidszorg, . Inventarisatie Onderzoeks- \& Ontwikkelingsprojecten Thuiszorg (Inventarization of Research- and Development projects in home care) LVT, Bunnik (1996).

11. B. van der Linden and E. Spithoven. Ledenlijst en projectomschrijvingen van het netwerk voor transmuraal werkenden (Member list of the transmural network) Rijksuniversiteit Utrecht, Utrecht (1996).

12. A. Donabedian. The Definition of Quality and Approaches To Its Assessment University of Michigan, Michigan (1980). 
Temmink, D., Francke, A.L., Kerkstra, A., Huyer Abu-Saad, H. Dutch transmural nurse clinics for chronic patients: a descriptive study. Patient Education and Counseling: 2000, 39(2-3), 177-184

\section{TABLES}

Table 1

Types of transmural nurse clinics distinguished by medical diagnosis

\begin{tabular}{|c|c|c|c|c|c|}
\hline Types of transmural nurse clinics & & & & \multicolumn{2}{|c|}{$\begin{array}{l}\text { Number of transmural nurse clinics } \\
(n=62)\end{array}$} \\
\hline \multicolumn{4}{|l|}{ Clinics for rheumatics } & \multicolumn{2}{|c|}{$24(39 \%)$} \\
\hline \multicolumn{4}{|l|}{ Clinics for diabetics } & \multicolumn{2}{|c|}{$16(26 \%)$} \\
\hline \multicolumn{4}{|l|}{ Clinics for CNSLD patients } & \multicolumn{2}{|c|}{$11(18 \%)$} \\
\hline \multicolumn{4}{|l|}{ Other clinics } & \multicolumn{2}{|c|}{$11(18 \%)$} \\
\hline \multicolumn{6}{|c|}{$\begin{array}{l}\text { Table } 2 \\
\text { Tasks of the specialist nurse at the transmural nurse clinic }\end{array}$} \\
\hline Tasks & $\begin{array}{l}\text { Rheumatic } \\
\text { clinics } \\
(n=24)\end{array}$ & $\begin{array}{l}\text { Diabetes } \\
\text { clinics } \\
(n=16)\end{array}$ & $\begin{array}{l}\text { CNSLD } \\
\text { clinics } \\
(n=11)\end{array}$ & $\begin{array}{l}\text { Other } \\
\text { clinics } \\
(n=11)\end{array}$ & $\begin{array}{l}\text { Number of clinics for } \\
\text { which the task is } \\
\text { reported }(n=62)^{4}\end{array}$ \\
\hline Patient education & 22 & 14 & 11 & 8 & $55(89 \%)$ \\
\hline Counseling & 15 & 5 & 2 & 5 & $27(43 \%)$ \\
\hline $\begin{array}{l}\text { Assessment of problems and } \\
\text { care needs/history taking }\end{array}$ & 10 & 4 & 3 & 4 & $21(34 \%)$ \\
\hline $\begin{array}{l}\text { Referring and guiding to other } \\
\text { professionals/organizations }\end{array}$ & 8 & 0 & 0 & 4 & $12(19 \%)$ \\
\hline Supporting the medical treatment & 0 & 1 & 0 & 3 & $4(6 \%)$ \\
\hline Foot inspection & 0 & 4 & 0 & 0 & $4(6 \%)$ \\
\hline $\begin{array}{l}\text { Others (tasks which are mentioned } \\
\text { at one clinic) }\end{array}$ & 2 & 4 & 1 & 3 & $10(16 \%)$ \\
\hline \multicolumn{6}{|c|}{$\begin{array}{l}\text { "Often more than one task was mentioned for a clinic. } \\
\text { Table } 3 \\
\text { Additional tasks of the specialist nurses (besides the transmural nurse clinic) }\end{array}$} \\
\hline Additional tasks & $\begin{array}{l}\text { Rheumatology } \\
\text { nurses }(n=24)\end{array}$ & $\begin{array}{l}\text { Diabetic nurses } \\
(n=16)\end{array}$ & $\begin{array}{l}\text { CNSLD nurses } \\
(n=11)\end{array}$ & $\begin{array}{l}\text { Other nurses } \\
(n=11)\end{array}$ & $\begin{array}{l}\text { Number of nurse } \\
\text { clinics for which the } \\
\text { task is reported }(n=62)^{n}\end{array}$ \\
\hline $\begin{array}{l}\text { Direct patient care } \\
\text { outside the clinic }\end{array}$ & 14 & 8 & 7 & 6 & $35(56 \%)$ \\
\hline $\begin{array}{l}\text { Improvement of competence } \\
\text { of professionals }\end{array}$ & 17 & 8 & 2 & 6 & $33(53 \%)$ \\
\hline $\begin{array}{l}\text { Co-ordination and } \\
\text { organization of care }\end{array}$ & 16 & 4 & 5 & 3 & $28(45 \%)$ \\
\hline $\begin{array}{l}\text { Innovation and health } \\
\text { management }\end{array}$ & 12 & 6 & 1 & 5 & $24(39 \%)$ \\
\hline Research & 6 & 3 & 2 & 2 & $13(21 \%)$ \\
\hline $\begin{array}{l}\text { Other additional tasks (tasks } \\
\text { which are mentioned at one clinic) }\end{array}$ & 1 & 3 & 0 & 0 & $4(6 \%)$ \\
\hline
\end{tabular}

"Often more than one goal is formulated for a clinic. 